\title{
Highly conserved serine residue 40 in HIV-1 p6 regulates capsid processing and virus core assembly
}

Jörg Votteler ${ }^{1 \dagger}$, Liane Neumann ${ }^{1 \dagger}$, Sabine Hahn ${ }^{1}$, Friedrich Hahn ${ }^{1}$, Pia Rauch ${ }^{1}$, Kerstin Schmidt ${ }^{1}$, Nicole Studtrucker ${ }^{1}$, Sara M $\varnothing$ Solbak², Torgils Fossen², Peter Henklein ${ }^{3}$, David E Ott ${ }^{4}$, Gudrun Holland ${ }^{5}$, Norbert Bannert ${ }^{5}$, Ulrich Schubert ${ }^{*}$

\begin{abstract}
Background: The HIV-1 p6 Gag protein regulates the final abscission step of nascent virions from the cell membrane by the action of two late assembly (L-) domains. Although p6 is located within one of the most polymorphic regions of the HIV-1 gag gene, the 52 amino acid peptide binds at least to two cellular budding factors (Tsg101 and ALIX), is a substrate for phosphorylation, ubiquitination, and sumoylation, and mediates the incorporation of the HIV-1 accessory protein Vpr into viral particles. As expected, known functional domains mostly overlap with several conserved residues in p6. In this study, we investigated the importance of the highly conserved serine residue at position 40, which until now has not been assigned to any known function of p6.

Results: Consistently with previous data, we found that mutation of Ser-40 has no effect on ALIX mediated rescue of HIV-1 L-domain mutants. However, the only feasible S4OF mutation that preserves the overlapping pol open reading frame (ORF) reduces virus replication in T-cell lines and in human lymphocyte tissue cultivated ex vivo. Most intriguingly, L-domain mediated virus release is not dependent on the integrity of Ser-40. However, the S40F mutation significantly reduces the specific infectivity of released virions. Further, it was observed that mutation of Ser-40 selectively interferes with the cleavage between capsid (CA) and the spacer peptide SP1 in Gag, without affecting cleavage of other Gag products. This deficiency in processing of CA, in consequence, led to an irregular morphology of the virus core and the formation of an electron dense extra core structure. Moreover, the defects induced by the S40F mutation in $\mathrm{p} 6$ can be rescued by the A1V mutation in SP1 that generally enhances processing of the CA-SP1 cleavage site.
\end{abstract}

Conclusions: Overall, these data support a so far unrecognized function of p6 mediated by Ser-40 that occurs independently of the L-domain function, but selectively affects CA maturation and virus core formation, and consequently the infectivity of released virions.

\section{Background}

The Gag polyprotein Pr55 of HIV-1 comprises the main structural components that are essential and sufficient for the formation of virus like particles (VLPs). Following synthesis in the cytoplasm, the Gag polyproteins are targeted to the plasma membrane where they assemble into immature budding particles. Concurrent with assembly and release of nascent virions, the Pr55 Gag

\footnotetext{
* Correspondence: Ulrich.Schubert@viro.med.uni-erlangen.de + Contributed equally

${ }^{1}$ Institute of Virology, Friedrich-Alexander-University, Erlangen, Germany Full list of author information is available at the end of the article
}

precursor is cleaved by the autocatalytically activated viral protease (PR), generating the matrix (MA, p17), capsid (CA, p24), nucleocapsid (NC, p7), and the p6 protein. This processing ultimately leads to structural rearrangement of Gag molecules within the virion and the formation of the typical cone shaped core structure, characteristic for a mature infectious particle [1]. MA mediates the plasma membrane targeting of Gag polyproteins and, after cleavage, lines the inner shell of the mature virion. CA forms the conical core shell encasing $\mathrm{NC}$, which regulates packaging and condensation of the viral genome [2-6]. The C-terminal p6 domain of Pr55,
C Biomed Central

(C) 2011 Votteler et al; licensee BioMed Central Ltd. This is an Open Access article distributed under the terms of the Creative Commons Attribution License (http://creativecommons.org/licenses/by/2.0), which permits unrestricted use, distribution, and reproduction in any medium, provided the original work is properly cited. 
the smallest known lentiviral protein, containing 52 amino acids, comprises a quite complex structural and functional organization and contains two distinct late assembly (L-) domains that regulate efficient separation of assembled virions from the cell surface. L-domains function as docking sites for components of ESCRT (endosomal sorting complex required for transport), cellular multi-protein complexes that are normally involved in the endocytotic recycling of cell surface receptors and in cytokinesis [4,7-17].

The L-domain activity of $\mathrm{p} 6$ is mainly driven by the ${ }^{7} \mathrm{PTAP}^{10}$ motif that is responsible for the recruitment of the primary budding factor Tsg101 (tumor susceptibility gene 101) to the virus assembly site [15,18-20]. Another region of $\mathrm{p} 6$ involves the residues ${ }^{36} \mathrm{YPLASL}^{41}$, comprising a cryptic $\mathrm{YPX}_{\mathrm{n}} \mathrm{L}$-type L-domain, which forms a degenerated version of the YPDL L-domain motif $\left(\mathrm{YPX}_{\mathrm{n}} \mathrm{L}, \mathrm{n}=3\right)$ found in equine infectious anemia virus (EIAV). This secondary L-domain in p6 represents a binding site for another cellular budding factor, AIP1/ ALIX (ALG-2 interacting protein 1/X, ALIX is used hereafter), a multifunctional ESCRT-associated regulator of intracellular protein transport [13,21]. In addition to the interaction with cellular ESCRT components, p6 mediates the incorporation of the HIV-1 accessory protein $\mathrm{Vpr}$ into virus particles. This incorporation was shown to be dependent on three motifs in p6, the ${ }^{15}{ }_{\text {FRFG }}{ }^{18}$ motif, the ${ }^{34} \mathrm{ELY}^{36}$ motif, and the ${ }^{41} \mathrm{LXXLF}^{45}$ motif [22-24].

Besides these well characterized interactions, p6 contains several highly conserved amino acids, some of which were shown or proposed to undergo posttranslational modification. In this study, we show that mutation of the highly conserved Ser residue in position 40 (Ser-40) leads to an irregular core assembly of the released virions, a reduced infectivity, and, thus, a disturbed virus replication capacity. The results support a novel function of $\mathrm{p} 6$ in virus maturation that occurs independently of L-domain function.

\section{Results}

\section{Mutation of Ser-40 has no effect on folding of p6}

HIV-1 p6 is located within one of the most polymorphic regions of the HIV-1 gag gene, yet the 52 amino acid peptide harbors one of the densest region of protein interacting domains in HIV-1. Figure 1A gives an overview of the previously reported binding domains of cellular (Tsg101, ALIX, ERK-2, SUMO-1, ubiquitin) and viral (Vpr) proteins within $\mathrm{p} 6$ from $\mathrm{HIV}-1_{\mathrm{NL} 4-3}$ and their relationship to the primary and secondary structures [25]. An alignment of consensus sequences, derived from all HIV-1 group $M$ subtypes, revealed that the known functional domains overlap - as expected - with conserved residues in p6.
While the PTAP L-domain is highly conserved, the conservation within the ALIX binding site varies to some extent (Figure 1). The ALIX-binding motif has been defined as (L)[FY]PX ${ }_{1-3} \mathrm{LXX}[\mathrm{IL}][21,26,27]$ and corresponds in $\mathrm{p} 6$ derived from $\mathrm{HIV}-1_{\mathrm{NL} 4-3}$ [28] to ${ }^{35}$ LYPLASLRSL $^{44}$, in which essential residues are in bold. Interestingly, the three amino acid motif ${ }^{35} \mathrm{LYP}^{37}$ at the start of the binding region is only poorly conserved (Figure 1) while both, Leu-41 and Leu-44, are highly conserved. These two residues together, with the downstream Phe-45, comprise the LXXLF binding domain for the HIV-1 accessory protein Vpr. From previous structural and mutational analysis, it can be concluded that Thr-39 and Ser-40 do not directly participate in the binding of p6 to ALIX $[21,27,29]$. Consistently, Thr-39 is not conserved, while in contrast, Ser-40 is highly conserved among HIV-1 group M isolates, indicating a function other than ALIX binding.

To investigate a potential function of Ser-40 in p6, the residue was mutated in the infectious molecular clone HIV-1 $1_{\text {NL4-3 }}$ [28] and an otherwise isogenic R5-tropic derivative thereof carrying the 005pf135 V3 loop region in Env [30]. In order to obtain replication competent viruses, the mutation was introduced in a way that does not affect the overlapping pol-ORF. In particular, Ser-40 of $\mathrm{p} 6$ overlaps in the pol-ORF with the cleavage site between the transframe $\mathrm{p}^{*}$ protein and PR. The only possibility to leave the pol-ORF unaffected was to exchange Ser-40 for Phe, creating the mutant S40F.

Considering this limitation in mutating p6, we wanted proof that the non-conservative S40F exchange does not disturb the secondary structure of $\mathrm{p} 6$ in the respective region. To ascertain whether the S40F mutation alters the C-terminal helix of $\mathrm{p} 6$, the synthetic $(s) \mathrm{p} 6^{23-52} \mathrm{~S} 40 \mathrm{~F}$ peptide was characterised by ${ }^{1} \mathrm{H}$ NMR spectroscopy [25]. Recently, we solved the structure of $s 6^{23-52}$ by NMR and found that the C-terminal fragment adopts the same structure as the full length molecule $s \mathrm{p} 6^{1-52}$. Therefore, it was legitimate to analyse the structure of the mutant and compare it with the $w t$ molecule. After complete assignment of the ${ }^{1} \mathrm{H}$ resonances of the NMR spectra of the peptide, NOE cross peaks important for secondary structure identification were identified. The observation of $\mathrm{NH}_{i}-\mathrm{NH}_{i+1}, \mathrm{NH}_{i}-\mathrm{NH}_{i+2}, \alpha \mathrm{H}_{i}-\mathrm{NH}_{i+2}$, $\alpha \mathrm{H}_{i}-\mathrm{NH}_{i+3}, \alpha \mathrm{H}_{i}-\mathrm{NH}_{i+4}$ and $\alpha \mathrm{H}_{i}-\beta \mathrm{H}_{i+3}$ NOEs, which are indicative of helical secondary structure, showed that, similarly to $w t s p 6^{23-52}, s p 6^{23-52} \mathrm{~S} 40 \mathrm{~F}$ has a preference for an $\alpha$-helical structure involving residues Ile-31 - Asp-48 under hydrophobic membranous conditions (50\% aqueous trifluorethanol (TFE) solution). Substitution of Ser- 40 with Phe did not change the position or number of residues included in the C-terminal helix compared with $w t s p 6^{23-52}$, and their structures appear to be similar. This is confirmed from a comparison of 


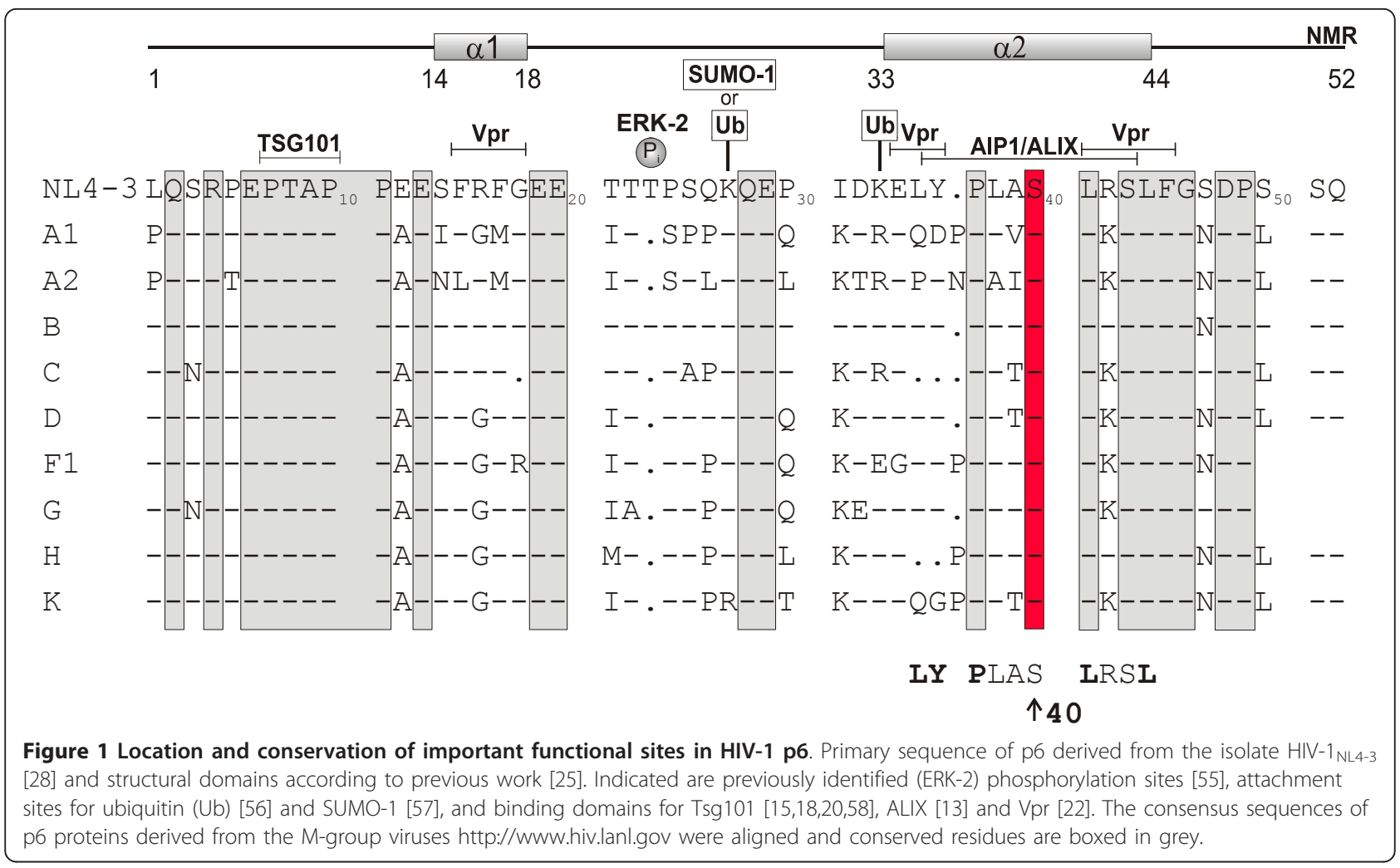

plots of the $\alpha$-proton chemical shifts relative to those of random coil values (Figure 2), which indicates that the substitution slightly stabilizes the region of the C-terminal helix comprised of residues Leu-41 - Leu-44 proximal to Phe-40.

\section{Mutation of Ser-40 in HIV-1 compromises virus replication} The finding that Ser-40 in p6 is highly conserved raises the question whether this amino acid is important for the function of $\mathrm{p} 6$ in HIV-1 replication. To investigate this, comprehensive replication studies of HIV-1 carrying mutation of Ser-40 in p6 were conducted in T cells and primary lymphocytes. Purified virus stocks of $w t$ HIV $-1_{\text {NL4-3 }}$ and the S40F mutant were generated in 293T cells and normalized for p24 content. First, parallel cultures of CEM T-cells were infected with 20 and $50 \mathrm{ng}$ of input virus, respectively, and samples of culture supernatants collected every other day were analyzed for secretion of virus particles by measuring the virus associated reverse transcriptase (RT) activity. The resulting replication profiles are shown in Figure $3 \mathrm{~A}$ and $3 \mathrm{~B}$. Mutation of Ser-40 resulted in a diminished replication capacity of HIV-1, which is observed as a delayed onset of virus replication (Figure 3A). Furthermore, increase of the input virus to $50 \mathrm{ng}$ resulted in a forward shift of the peak of virus replication. Yet, the overall virus production was still reduced, indicating altogether a compromised replication capacity of the Ser-40 mutant of p6 (Figure 3B). To further evaluate the relevance of Ser-40 in p6, replication studies were conducted in lymphoid cells, derived from human tonsillary tissue, cultivated as aggregate cultures (HLAC) [31]. The HLAC system has been reported to be of comparable value to that of previously described human lymphoid tissue cultures (HLT) where virus replication is studied in tissue blocks [32,33]. Generally, both HLACs and HLTs, support productive HIV-1 replication independently of the coreceptor tropism and do not require artificial exogenous activation of host cells [32,33]. Parallel cultures of HLAC were infected with X4-tropic or R5-tropic HIV$1_{\mathrm{NL} 4-3}$ carrying mutation of Ser-40. Samples of culture supernatant were harvested every third day, and secretion of viral particles was determined by measuring the virus associated $\mathrm{RT}$ activity. The resulting replication profiles obtained in tissue samples, derived from two different donors for X4-tropic strains, are shown in Figure $3 \mathrm{C}$ and $3 \mathrm{E}$, and for R5-tropic variants in Figure 3D and $3 \mathrm{~F}$. Consistent with results obtained in CEM cells (Figure 3A, 3B), mutation of Ser-40 resulted in a reduced replication capacity of both X4-tropic and R5tropic viruses.

\section{Mutation of Ser-40 in p6 does not affect virus release but disturbs CA maturation}

To analyze whether the decreased replication capacity of the Ser-40 mutant is due to either a reduction of virus 


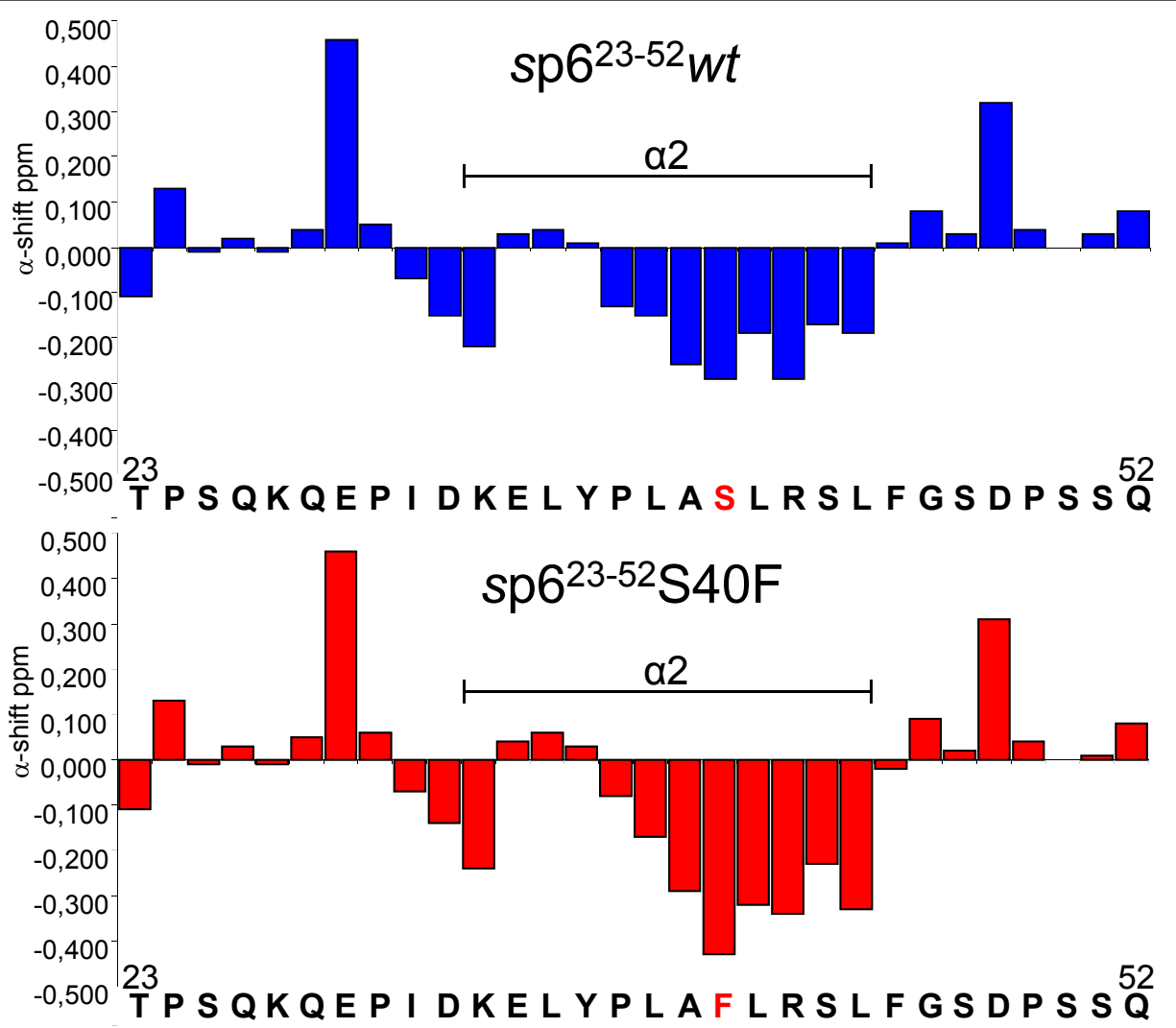

Figure 2 Mutation of Ser-40 does neither affect the secondary structure of p6, nor the interaction with ALIX. A) Chemical shift differences (ppm) of the $\alpha$-protons between the experimental values and those for residues in a random coil for $s p 6^{23-52} W t$ and $s p 6^{23-52} S 40 F$ in $50 \%$ aqueous TFE at pH 3 at $300 \mathrm{~K}$. All positive values for $\mathrm{N}$-terminal residues adjacent to proline residues at positions 24, 30,37 and 49 arise from an inherent effect of proline and not out of a structural perturbation. This was explained in detail previously [25].

particle production or to a loss of infectivity of the released virions, we first investigated whether Ser-40 is somehow involved in the L-domain mediated assembly and release of virus particles. Virus release kinetics were studied by pulse chase metabolic labeling experiments. Parallel cultures of HeLa cells were transfected with the env-deleted HIV-1 $1_{\mathrm{NL} 4-3}$ subgenomic expression vector pNLenv1 [34,35], encoding either $w t$ p6 or the S40F mutant. Cells were pulse labeled with $\left[{ }^{35} \mathrm{~S}\right]$-methionine for 15 minutes and chased for up to 4 hours. At each time point indicated, samples of cells were harvested, and VLPs released into the supernatants were collected by centrifugation and processed for immunoprecipitation with Gag-specific antibodies. Immunoprecipitated proteins were separated by SDS-PAGE and analyzed by fluorography (Figure 4A). The amounts of Gag recovered from virus and cell lysates were quantified by image analysis. The release of VLPs was calculated as percentage of Gag proteins found in the virus fraction, relative to the total amount of Gag recovered from virus and cell fractions and plotted as a function of time (Figure 4B). Clearly, virus release was not affected by mutation of Ser-40. However, quantification of the CA processing products p 25 and p 24 revealed a significant reduction in the processing rate of p25 to p24 for the S40F mutant (Figure 4C). Thus, Ser-40 somehow regulates the proteolytic maturation of the CA-SP1 Gag processing intermediate, without affecting the overall efficiency of virus release.

S40F mutation reduces specific infectivity of the virions Having shown that mutation of Ser-40 in p6 does not affect L-domain mediated virus release but disturbs maturation of CA, we analyzed the role of this Ser residue in maturation of progeny virions. To measure the specific infectivity of the mutant, HeLa TZM-bl cells were infected with individual virus stocks standardized for p24 content and infectivity was determined by $\beta$-galactosidase assay. Consistent with virus replication data, mutation of Ser-40 reduced the infectivity by approximately 6-10 fold when compared to the $w t$ virus (Figure 5).

\section{Mutation of Ser-40 has no effect on ALIX mediated virus release}

Ser-40 residue is located within the previously identified ${ }^{36}$ YPLASL $^{41}$ ALIX binding sequence, although shown 


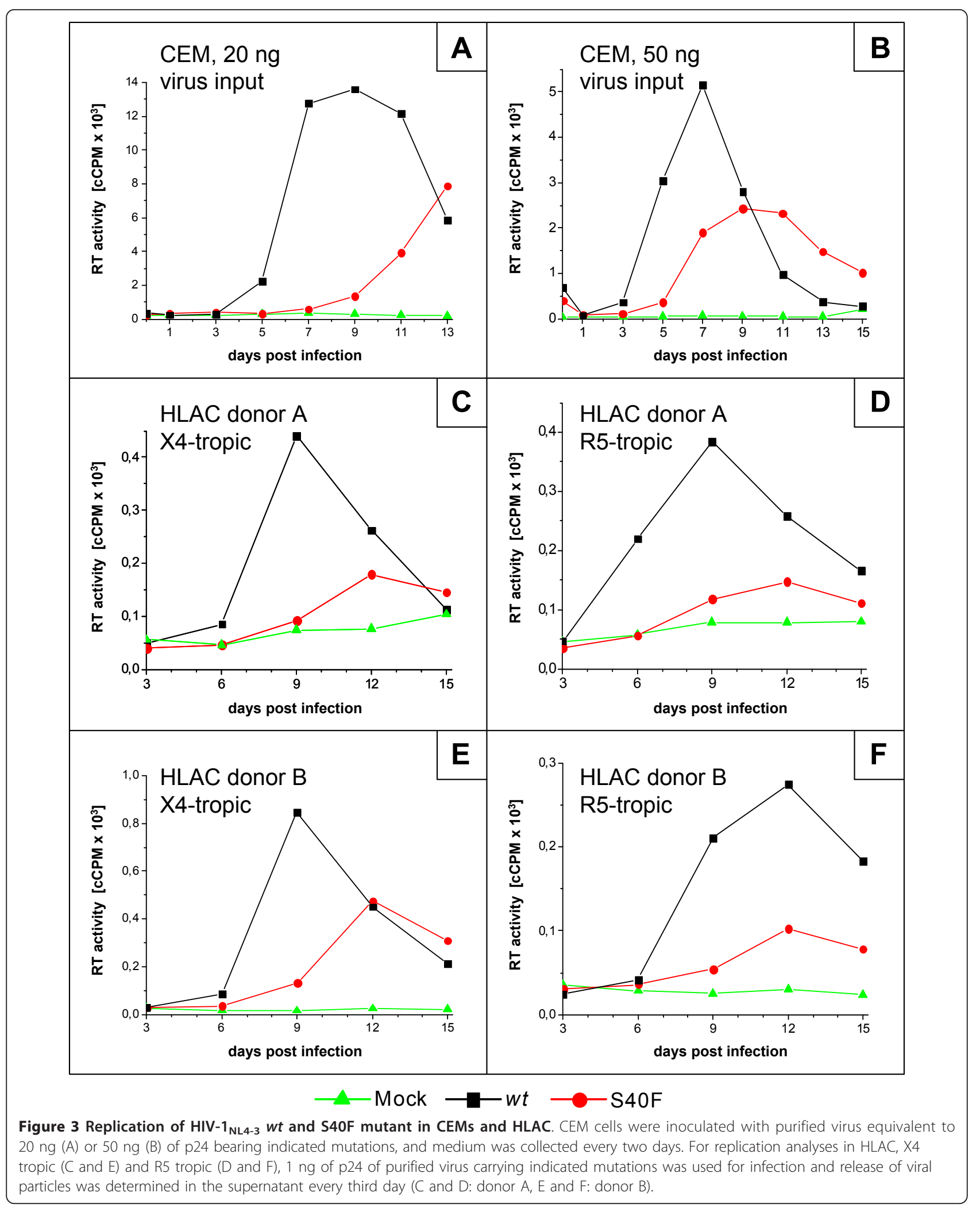




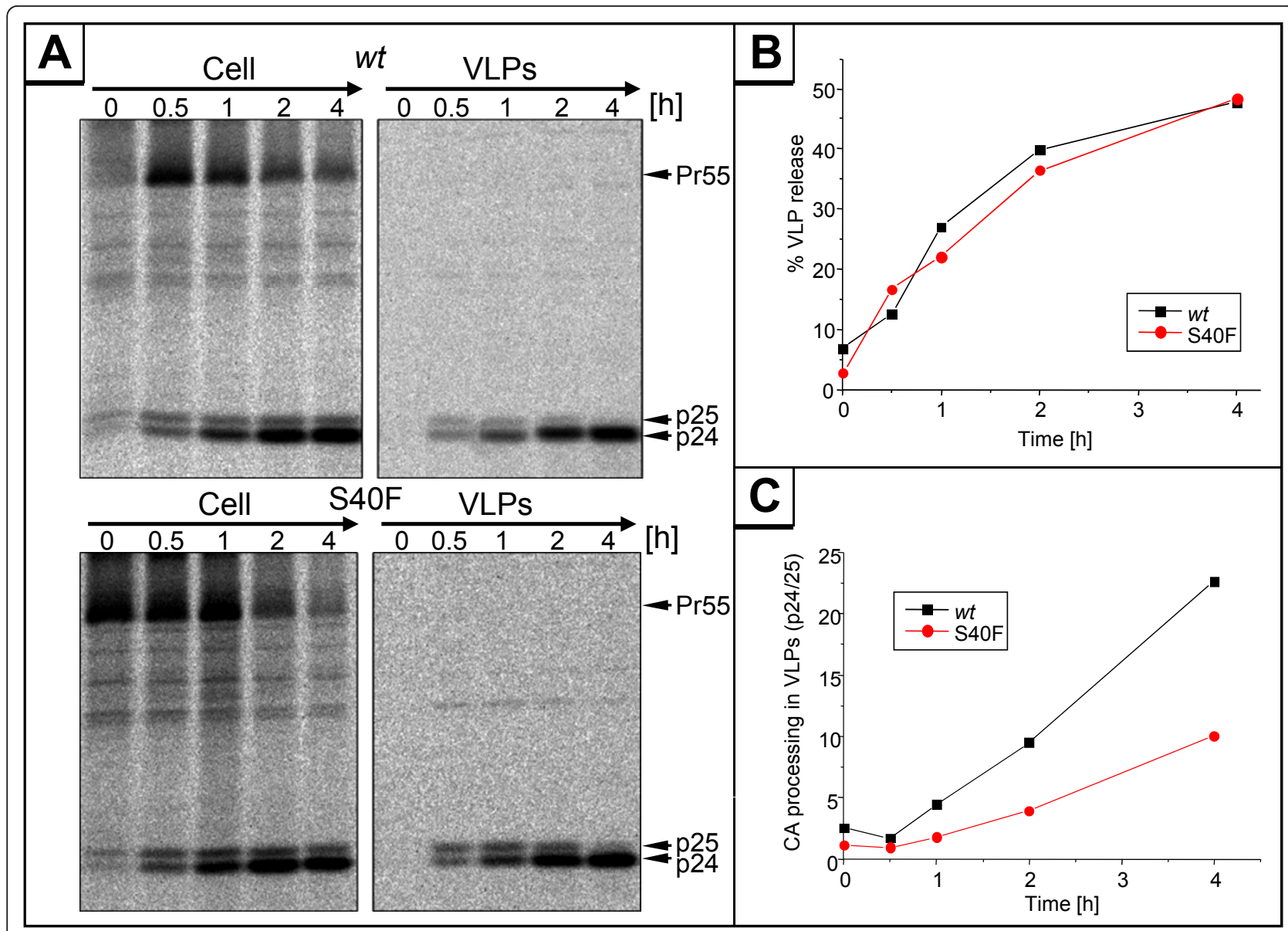

Figure 4 Gag processing and release of virions. (A) Phosphorimages of SDS-PAGE gels of immunoprecipitations of ${ }^{35} \mathrm{~S}$ pulse-chase-labeled Gag protein immunoprecipitates are presented for cell and viral lysates from HeLa cells transiently transfected with either pNLenv or pNLenv S4OF. (B) Percentage of Gag released from the cell presented as the amount of Gag found in virus particles versus the total amount of Gag recovered form cell and virus lysates. (C) The rate of CA processing was estimated by calculating the ratio of mature CA p24 versus the CA precursor p25 detected in the cell and virus lysates at different time points.

not to be involved in the interaction with ALIX directly $[21,29]$. It was further reported that mutation of either Leu-41 or Leu-44 directly adjacent to Ser-40 exhibit a similar phenotype to that observed for the S40F mutant in terms of CA processing [36]. Therefore, it was legitimate to investigate whether mutation of Ser-40 affects the functional interaction between ALIX and p6. We first examined the ability of ALIX to rescue the release of an $\mathrm{HIV}-1_{\triangle \mathrm{PTAP}} \mathrm{L}$-domain mutant by overexpression in the absence of the Ser-40 [21,37]. The S40F mutation was cloned into a variant of $\mathrm{HIV}-1_{\mathrm{NL} 4-3}$ where the PTAP motif was replaced by LIRL $\left(\mathrm{HIV}-1_{\triangle \mathrm{PTAP}}[38]\right)$. 293T cells were cotransfected with plasmids encoding ALIX and either HIV-1 $1_{\triangle \mathrm{PTAP}}$ or HIV-1 $1_{\triangle \mathrm{PTAP} / \mathrm{S} 40 \mathrm{~F} \text {. As }}$ control, cells were cotransfected with $\mathrm{HIV}-1_{\triangle \mathrm{PTAP} / \Delta \mathrm{YP}}$, where the ALIX binding site $\mathrm{YPX}_{3} \mathrm{~L}$ was replaced by $\mathrm{SRX}_{3} \mathrm{~L}$. As previously reported, this mutation completely abrogates ALIX mediated rescue of release of HIV$1_{\triangle \mathrm{PTAP}}$ variants [21]. Gag processing and release of infectious virions were determined 24 hours post transfection by Western blot and single round infection of TZM-bl cells. The results shown in Figure 6A demonstrate that in the presence of the intact ALIX binding site in p6, overexpression of ALIX dramatically stimulated virus release by more than 10 -fold as shown by Western blot and single round infection of TZM-bl cells (Figure 6A, lanes 1 and 2). Consistent with previous results $[21,27]$, the mutation of the minimal ALIX binding motif further reduced virus release even below the residual budding of an $\mathrm{HIV}-1_{\triangle \mathrm{PTAP}}$ mutant (Figure 6A, lane 5), and completely prevents rescue of the HIV$1_{\triangle \mathrm{PTAP}}$ variant by overexpression of ALIX (Figure 6A, lane 6) [21]. Mutation of Ser-40 also reduced the residual release of the HIV-1 $1_{\triangle \mathrm{PTAP}}$ mutant (Figure 6A, lane 3 ). In contrast to the $\triangle \mathrm{YP}$ mutation, in the presence of the S40F mutation, overexpression of ALIX still efficiently rescued the release of the HIV-1 $1_{\triangle \mathrm{PTAP}}$ mutant (Figure 6A, lane 4 upper panel). However, overexpression of ALIX did 


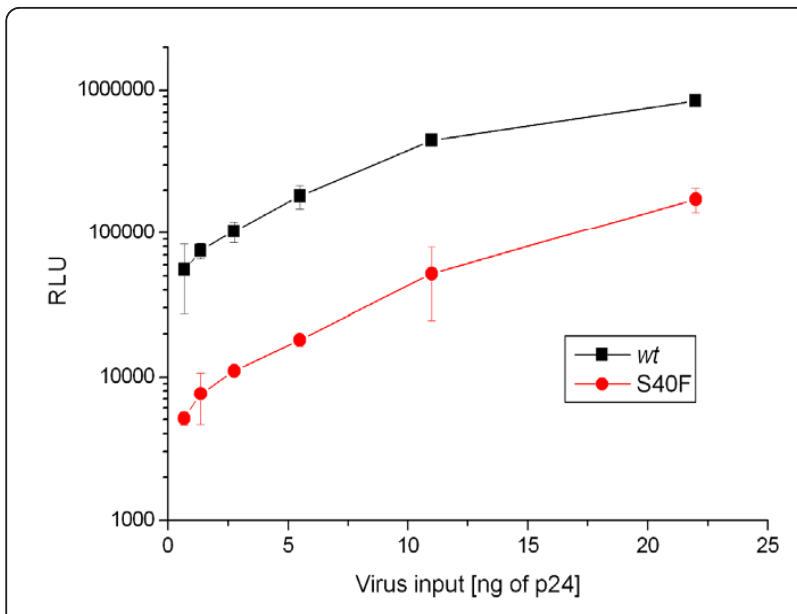

Figure 5 Specific infectivity of HIV-1 ${ }_{\mathrm{NL} 4-3}$ wt and p6-mutants. TZM-bl cells were infected with purified virus preparations standardized for p24. Infectious titers were determined by measuring $\beta$-galactosidase activity as described in Materials and Methods (RLU: relative light units).

not restore the infectivity of the S40F mutant virions (Figure $6 \mathrm{~A}$, lane 4 lower panel), indicating that the loss of infectivity induced by mutation of Ser- 40 occurs independently of the ALIX-p6 interaction.

To further uncouple the phenotype induced by S40F mutation from the underlying L-domain function of the ALIX binding site, we investigated whether ALIX can rescue the infectivity of the S40F mutant in the context of a functional PTAP motif. To this end, 293T cells were co-tranfected with HIV-1 encoding either $w t$ p6 or the S40F mutant and ALIX. Release of infectious virions was determined 24 hours post transfection by single round infection of TZM-bl cells. Consistent with previous results, the S40F mutation reduced the infectivity of released virions by $\sim 5$-fold (Figure $6 \mathrm{~B}, 1$ and 3 ). While overexpression of ALIX had no significant influence on the infectivity of $w t$ HIV-1 (Figure 6B, 2), ALIX also could not restore the reduced infectivity of the S40F mutant (Figure 6B, 4).

In order to determine whether the ALIX mediated rescue of the HIV-1 $1_{\triangle \mathrm{PTAP}}$ variant of the S40F is still comparable to the control, we measured the requirement of ALIX for HIV-1 $1_{\triangle \mathrm{PTAP}}$ release at varying ALIX concentrations. 293T cells were cotransfected with HIV$1_{\triangle \mathrm{PTAP}}$ and increasing amounts of ALIX expression plasmids. Subsequent determination of virus release by Western blot (Figure 7A) showed that in the presence of the S40F mutation similar amounts of ALIX were required to stimulate virus release (Figure 7A and 7B). Notably, ALIX substantially improved the processing of CA of the HIV-1 $1_{\triangle \mathrm{PTAP}}$ mutant. In contrast, CA processing of the HIV-1 $1_{\triangle \mathrm{PTAP} / \mathrm{S} 40 \mathrm{~F}}$ mutant was further impaired, compared to the HIV-1 $1_{\triangle \mathrm{PTAP}}$ mutant, and was

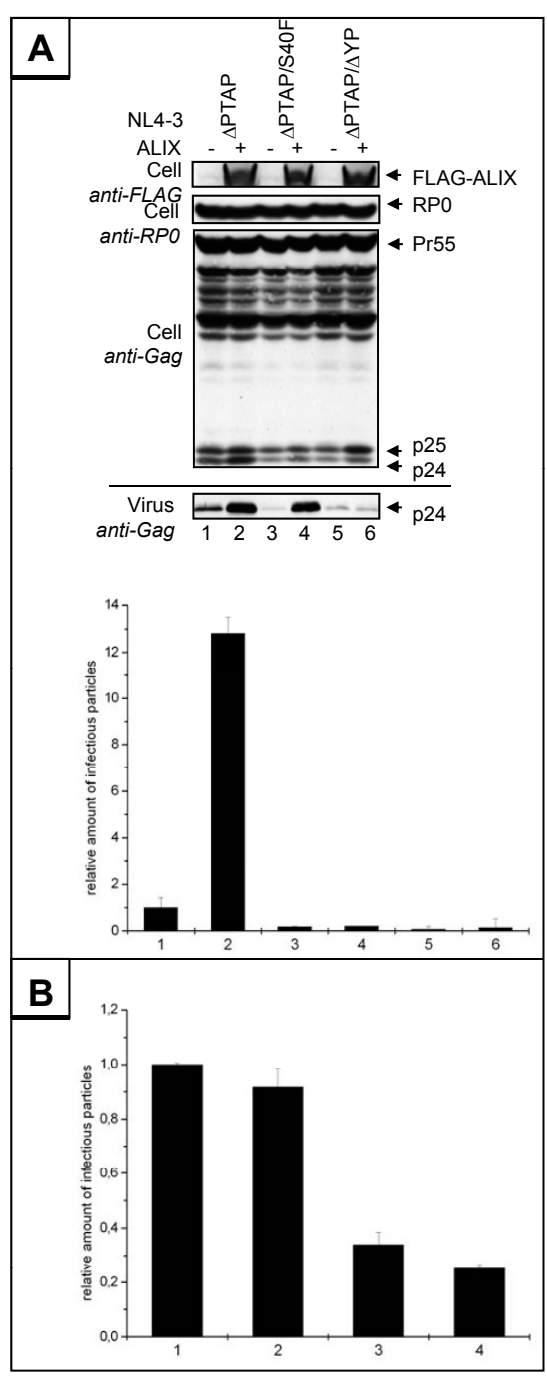

Figure 6 S40F mutation has no effect on ALIX mediated virus release. (A) Rescue of budding of the Ser- 40 mutant by ALIX. Virus release, Gag processing, and exogenous expression of ALIX were analyzed by Western blot (upper panel). Ribosomal P0 antigen (RP0) was used as loading control. The amounts of infectious units released from the cells were analyzed by $\beta$-galactosidase quantification after infection of TZM-bl cells (lower panel). Shown are virus infectivities relative to the HIV-1 ${ }_{\triangle \mathrm{PTAP}}$ control $\pm \mathrm{SD}$. Lane 1 shows HIV-1 ${ }_{\triangle \mathrm{PTAP}}$ mutant cotransfected with the empty control vector, lane 2 shows $\mathrm{HIV}^{-1} 1_{\triangle \mathrm{PTAP}}$ mutant cotransfected with a FLAGALIX expression plasmid, lanes 3 and 4 show the HIV-1 ${ }_{\triangle P T A P / \Delta Y P}$ double mutant cotransfected with the empty control plasmid and the vector expressing $\mathrm{V} 5$-POSH, respectively, lanes 5 and 6 show the HIV-1 $1_{\triangle P T A P / \triangle Y P}$ double mutant cotransfected with the empty control plasmid and the vector expressing $\mathrm{V} 5-\mathrm{POSH}$, respectively. (B) Overexpression of ALIX does not rescue infectivity of the S4OF mutant. The amounts of infectious units released from the cells analyzed were by $\beta$-galactosidase quantification after infection of TZM-bl cells. Shown are virus infectivities relative to the HIV-1 control \pm SD. 1: HIV-1 contransfected with the empty control vector, 2: HIV-1 cotransfected with a FLAG-ALIX expression plasmid, 3: HIV$1_{\text {S4OF }}$ cotransfected with the empty control vector, 2 : HIV-1 ${ }_{\text {S4OF }}$ cotransfected with a FLAG-ALIX expression plasmid. 


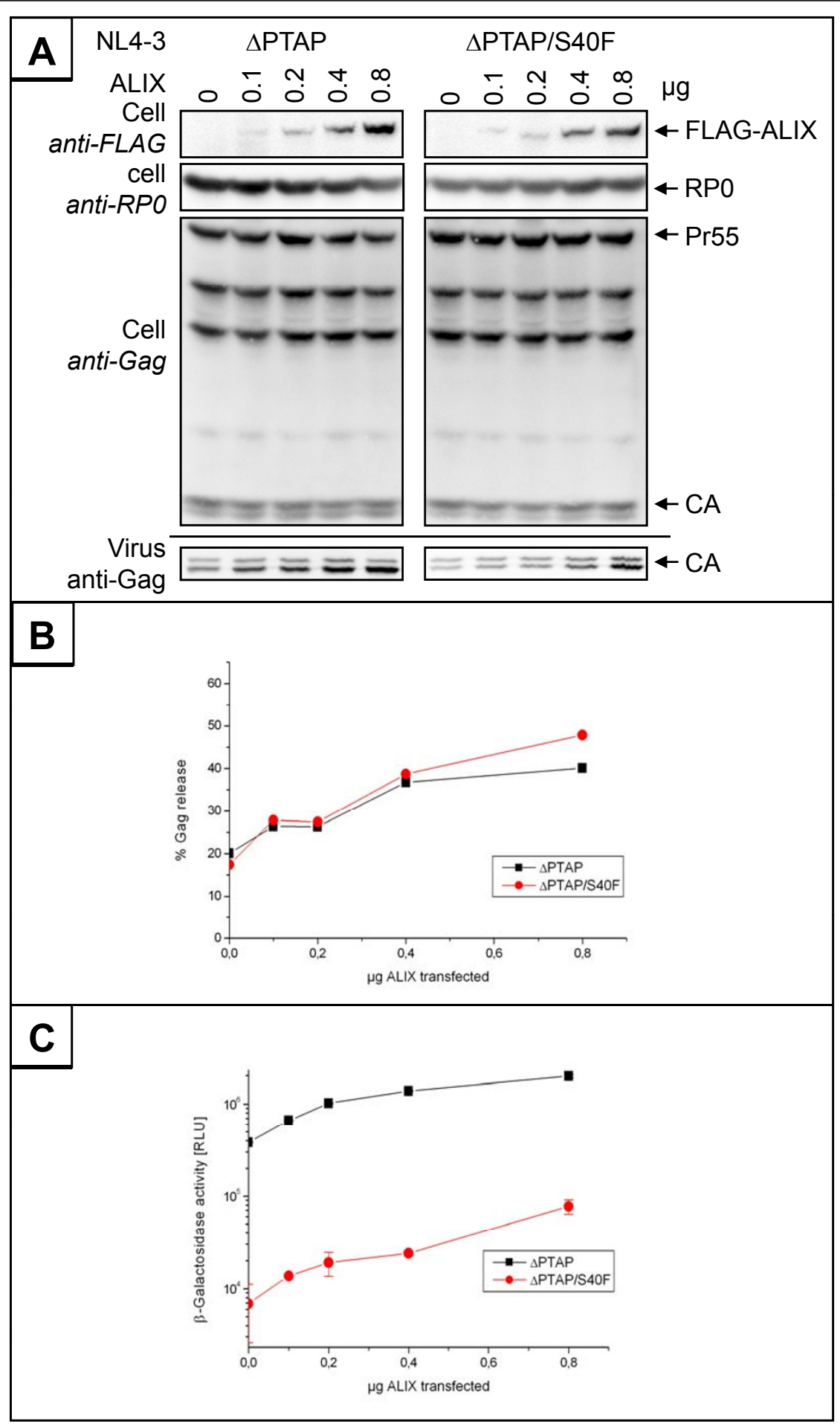

Figure 7 Mutation of Ser-40 has no effect on ALIX mediated virus release. (A) 293T cells were cotransfected with HIV-1 $1_{\triangle P T A P}$ Or HIV-1 $1_{\triangle P T A P}$ / S40F and increasing amount of ALIX plasmid. (B) Quantification of Western blot data using AIDA Software (Raytest). Shown is the amount of Gag release determined by the ratio of virus associated Gag/total Gag expressed. (C) The amount of infectious units released from the cells was analyzed by $\beta$-galactosidase quantification after infection of TZM-bl cells. 
not rescued by overexpression of ALIX (Figure 7A). This was further supported by the notion that the infectivity of the S40F mutant virions was substantially reduced and could not be restored by overexpression of ALIX (Figure 7C). Taken together, the data indicate that the interaction of $\mathrm{p} 6$ with ALIX is not affected by replacing the conserved Ser-40 by Phe, and the phenotype induced by this mutation occurs independently of the ALIX mediated L-domain function of p6 in this region.

The S40F mutation does neither affect cleavage of Gag products, other than CA, nor incorporation of Env

In order to rule out the possibility that mutation of Ser40 also affects processing of Gag proteins other than CA, virus preparations were analyzed by Western blotting using antibodies specific for NC or MA. Virus particles prepared by transient transfection of 293T cells were purified by centrifugation through a $20 \%$ sucrose cushion and standardized for p24 content by ELISA. Equal amounts of p24 were loaded on SDS-PAGE and analyzed by Western blotting. The amount of MA and $\mathrm{NC}$ proteins in S40F mutant viruses was similar to that of $w t$ virions, indicating that maturation of these Gag proteins is not affected by the S40F mutation (Figure $8 \mathrm{~A})$. Even with the relatively low resolution of the SDSPAGE system, the disturbed processing of CA from p25 to p24 was detectable (Figure 8A).

It was shown previously that mutations of $\mathrm{p} 6$ in this area, in particular, mutations of Tyr-36 and Leu-41 produce mutants that fail to package Env proteins into virus particles [39]. Since Ser-40 is located directly adjacent to Leu-41, we wanted to exclude that the reduced replication capacity and infectivity of the S40F mutant is due to reduced Env incorporation. To this end, purified virions standardized for p24 content were analyzed by Western blotting using Env specific antibodies. As shown in Figure 8B, the S40F mutation had no influence on Env incorporation into virus particles.

\section{Electron microscopy analysis of p6 S40F mutants}

Next, we examined the effects of the S40F mutation on assembly, release, and virion morphology by thin-section electron microscopy (Figure 9). HeLa cells transiently transfected with plasmids encoding $\mathrm{HIV}-1_{\mathrm{NL} 4-3}$ and mutants thereof were drawn into cellulose capillary tubes 24 hours post transfection. The cellulose capillary tubes retain secreted virions, thereby obviating the need for centrifugation steps that usually affect the native virion structure. In agreement with our biochemical data, accumulation of virions tethered at the cell membrane, a phenotype commonly observed for L-domain mutants in p6, was not observed for the S40F mutant (data not shown). However, and most intriguingly, mutation of Ser-40 in p6 led to the formation of aberrant virus particles, characterized by irregularly shaped viral cores and the formation of closely neighboring electron-dense lateral bodies, as indicated in Figure 9A. These irregularly shaped cores and lateral bodies were not observed in the $w t$ and the $\Delta \mathrm{YP}$ mutant, again indicating that this phenotype occurs independently of the ALIX-Gag interaction. As we observed a deficiency in CA processing of p25 to p24 in the virions containing the S40F mutation (Figure 9), we investigated whether this defect in virus core assembly is a consequence of imperfect CA processing. A previously characterized CA5 mutant was generated in HIV-1 $1_{\mathrm{NL} 4-3}$ that is incapable of processing p25 to p24 and was shown to exhibit a similar defect of core assembly [40]. Indeed, the phenotype observed for CA5

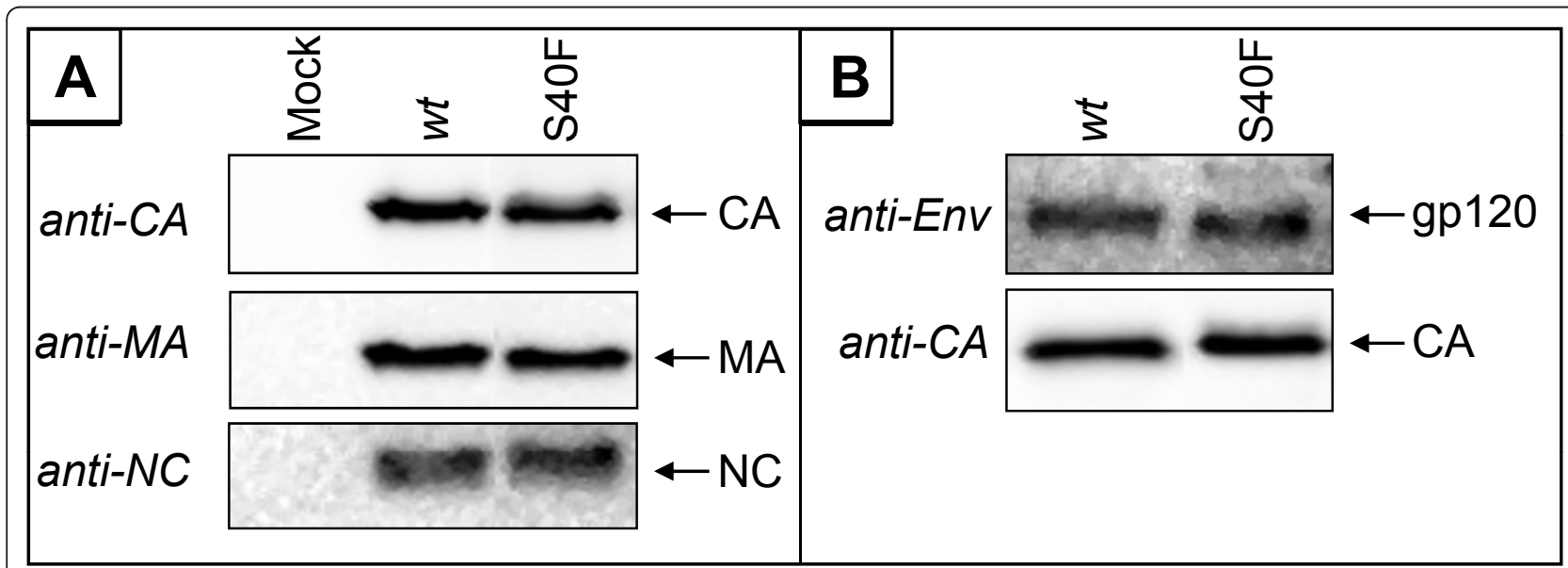

Figure 8 Analysis of Gag processing products and Env incorporation in wt HIV-1 and S40F mutant virions. (A) Analysis of Gag processing in VLPS. VLPs produced in $293 T$ cells transiently transfected with $\mathrm{p} \Delta \mathrm{R}$ and $\mathrm{p} \Delta \mathrm{R}_{\mathrm{S} 40 \mathrm{~F}}$ were purified and analyzed by Western blot using antibodies against CA, MA and NC. (B) Analysis of Env incorporation in VLPS. VLPs produced in $293 T$ cells transiently transfected with p $\triangle R$ and $\mathrm{p} \triangle \mathrm{R}$ S40F were purified and analyzed by Western blot using antibodies against Gag and Env. 

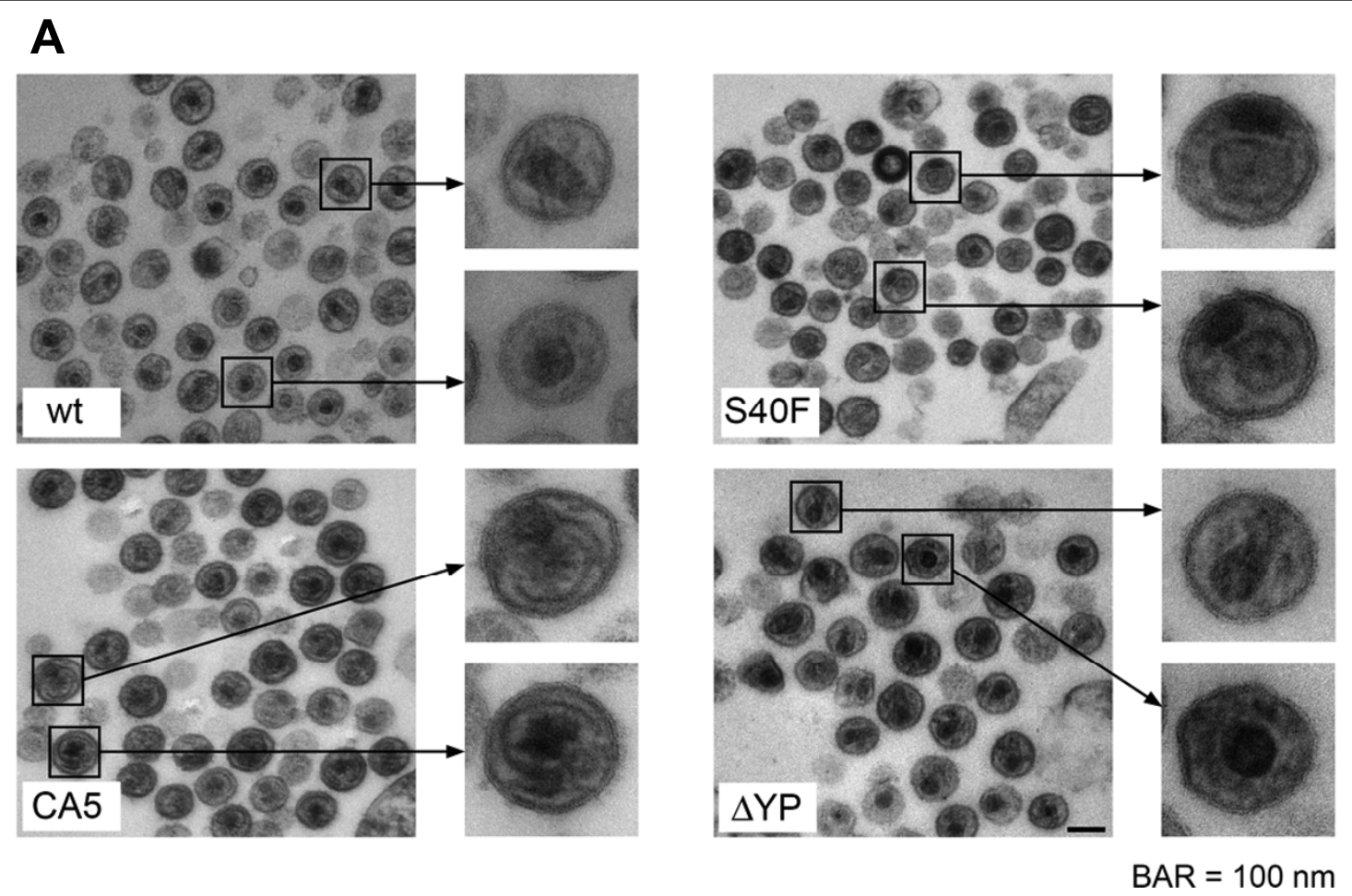

B

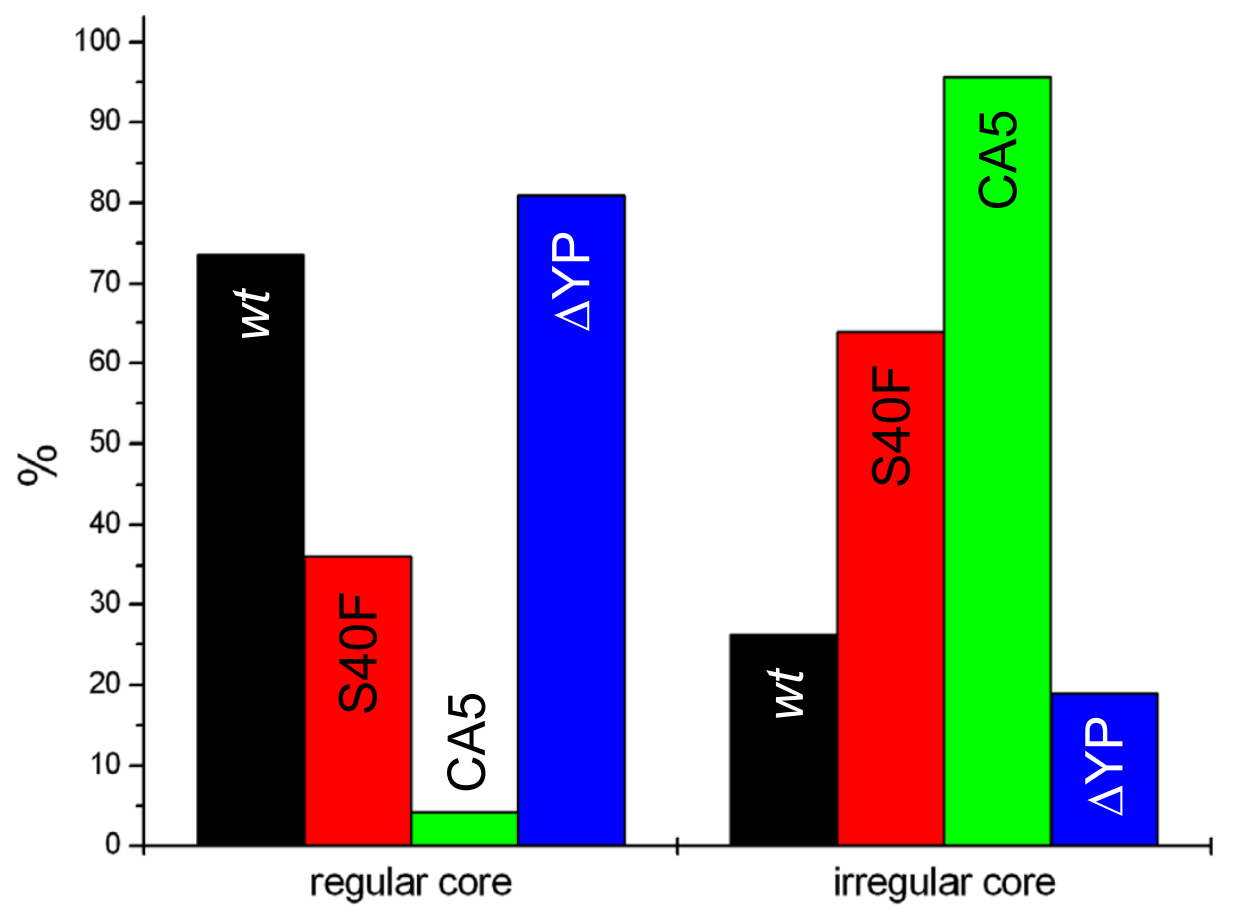

Figure 9 Core morphology of wild type and mutant HIV-1 particles. (A) Electron micrographs showing thin sections of HeLa SS6 derived extra cellular particles of $\mathrm{HIV}-1_{\mathrm{NL}-43}$ Wt, the S40F mutant, the CA-SP1 Gag cleavage deficient mutant CA5, and the ALIX binding site mutant $\triangle \mathrm{YP}$. A higher-magnification view of representative particles illustrates the dominating core structures. (B) Quantitative assessment of the relative amount of particles with regular and irregular core morphology. About 100-120 unselected particles of the wt virus and each mutant were evaluated. The data are representative for four independent experiments. 
by analyzing the core structures of this mutant clearly resembles that of the S40F mutant (Figure 9A).

To evaluate quantitatively this morphological phenomenon, cores of 100 - 120 virons were counted and the percentages of irregular core structures relative to $w t$ virions were calculated (Figure 9B). Obviously, mutation of Ser-40 significantly increases the amount of virions containing aberrant, irregularly shaped virus cores. Moreover, the CA5 mutant, in which CA processing is blocked completely, shows the same phenotype as that of the S40F mutant, further supporting the notion that Ser- 40 governs the processing of CA by a yet unidentified mechanism.

\section{Defect in CA maturation of the S40F mutant can be rescued by mutation in the CA-SP1 cleavage site}

As described above, the S40F mutation increases the ratio of p25 to mature p24. Our data, together with previous results from others, suggest that this disturbed CA processing subsequently leads to an irregular morphology of the virus core and thus, to reduced virus infectivity of the virions. This prompted us to investigate, whether restoring the CA processing by introducing specific mutations into the CA-SP1 cleavage site can rescue the defects in core assembly and infectivity induced by the S40F mutation. It is known that the affinity of the PR to the cleavage site between CA and SP1 is weak compared to other proteolytic cleavage sites in Gag [41,42]. The A1V mutation in the SP1, which previously was identified to confer resistance to the CA-maturation inhibitor Bevirimat [43], enhances the affinity of the viral protease to the CA-SP1 cleavage site. Thus, the A1V mutation in SP1 was introduced into the HIV-1 $1_{\mathrm{NL4}-3}$ backbone in combination with the S40F mutation in p6. Western blot analysis of purified virions revealed that, by introducing the A1V mutation, CA processing is substantially enhanced in both, the $w t$ and the S40F mutant virions (Figure 10A). Furthermore, the A1V/S40F mutant displayed a similar CA processing compared to the $w t$.

Consequently, we wanted to examine whether this enhanced CA processing affects virus core assembly. Therefore, virion structure of the A1V mutants was analyzed by thin-section electron microscopy. Cores of $100-120$ virons were counted and the percentages of irregular core structures relative to $w t$ virions were calculated (Figure 10B). The S40F mutation again substantially increases the amount of virions containing aberrant, irregularly shaped virus cores. The A1V mutation had only marginal effects on the core morphology of $w t$ HIV-1. However, in the case of the S40F mutant, introducing the $\mathrm{A} 1 \mathrm{~V}$ mutation largely improves virus core assembly (Figure 10B).

Since enhancing the CA processing rate rescues the defect of viral core assembly, we subsequently wanted to

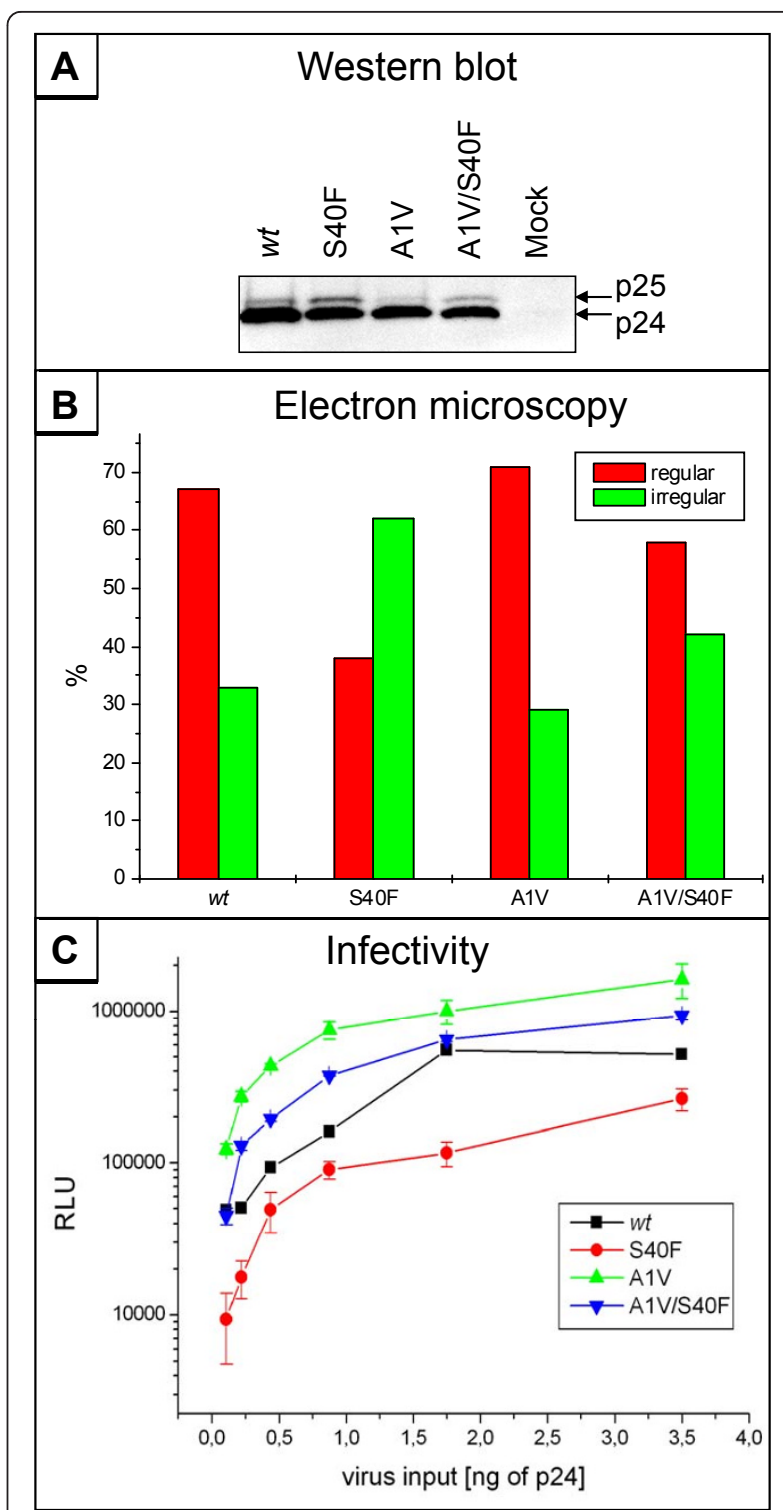

Figure 10 Rescue of CA maturation by A1V mutation in CASP1 cleavage site. (A) Western blot analysis of CA processing in VLPS. VLPS derived from $293 T$ cells transfected with $p \Delta R$ and $p \triangle R_{S 40 F}$ in combination with the A1V mutation in SP1 were purified and analyzed by Western blot using antibodies against CA. (B) Quantitative assessment of the viral core morphology derived from electron micrographs for the above indicated mutants. About 100120 unselected particles of the wt virus and each mutant were evaluated. (C) Specific infectivity of HIV-1 NL4-3 $w t$ and S4OF mutant in combination with the A1V mutation. TZM-bl cells were infected with virions derived from pNL4-3 wt and S4OF in combination with SP1 AIV and infectious titers were determined by measurement of the $\beta$-galactosidase activity (RLU: relative light units).

analyze whether this improved core formation also affects the infectivity of the virions. To measure the specific infectivity, HeLa TZM-bl cells were infected with individual virus stocks standardized for $\mathrm{p} 24$ content and infectivity was determined by $\beta$-galactosidase assay. 
The A1V mutation alone enhances the specific infectivity of the virons by 4-fold (Figure $10 \mathrm{C}$ ). Introducing the A1V mutation enhances the specific infectivity of the virions of the otherwise attenuated S40F mutant to almost $w t$ levels (Figure 10C), indicating that the deficiency in CA processing is the major determinant for the reduced infectivity of the S40F mutant.

\section{Discussion}

In this study we demonstrate that mutation of the highly conserved Ser-40 interferes with Gag processing and virus core formation. Although Ser-40 in HIV-1 p6 is highly conserved among HIV-1 isolates, it is not involved in any of the functional motifs described so far, neither the ALIX nor the Vpr binding site. Therefore, it was legitimate to speculate that Ser-40 is involved in another, until now unrecognized function of p6. However, it should be noted that the position of Ser-40 in the nucleotide sequence of HIV-1 overlaps with the $\mathrm{p} 6 \% / \mathrm{PR}$ cleavage site in the overlapping pol-ORF, which limits the probability of mutations in this respective area and might contribute to the high conservation of this amino acid. Nevertheless, our findings of a compromised replication capacity and reduced infectivity of the Ser-40 mutant viruses support the assumption that Ser-40 has an important function directly associated with p6.

Notably, virus release kinetic was not reduced for the S40F mutant providing first evidence that the L-domain function of p6 is not affected by mutation of Ser-40. This was supported further by the observation that the ability of ALIX to rescue HIV-1 $1_{\triangle \text { PTAP }}$ L-domain mutant viruses was not influenced by the S40F mutation. Although Ser-40 is located within the ALIX binding region in $\mathrm{p} 6$, previous structural investigations indicated that Ser-40 itself does not participate in the binding of p6 to ALIX $[21,27,29]$. The fact that the Ser-40 mutant was still fully active in terms of L-domain function further supports the notion, that the mutation introduced into p6 did not disturb the overall structure of the molecule in this respective region. In consistency, structural calculations indicated that the non-conservative exchange of Ser-40 to Phe does not change the ability of the molecule to adopt a helical structure. In fact, the C-terminal $\alpha$-helix is conserved in the S40F mutant, as it was established by NMR studies of the C-terminal peptides $s \mathrm{p}^{23-52}$.

Yet, as shown previously, the phenotypes induced by mutations in the ALIX binding site are depending on the type of amino acid that is mutated [36]. Mutation of the ${ }^{35} \mathrm{LYP}^{37}$ sequences in the ALIX binding site reduces release and infectivity of $\mathrm{HIV}-1$ virions, which otherwise exhibit normal Gag processing $[27,36]$. In contrast, mutations of Leu-41 and Leu-44 have no impact on virus release but increase the ratio of p25 to mature p24, similar to the phenotype we observed for mutation of Ser-40 [36]. Unlike the typical phenotype of Ldomain mutants, these mutants interfere somehow specifically with the final step in maturation of CA. It is currently not clear, whether this phenotype is in some way associated with the ALIX-p6 interaction. While mutations of Leu-41 and Leu-45 disrupt binding to ALIX, mutation of Ser-40 apparently has no influence on this interaction. Thus, it might also be possible, that this area in p6 harbors another function that, independent of L-domain activity, requires a so far unrecognized cellular interaction partner.

Maturation of the Gag processing intermediate p25 to mature CA p24, e. g. the cleavage of the CA-SP1 junction by the PR, appears to be one of the last steps of Gag processing $[41,42]$. It was previously demonstrated that mutating the junction between CA and SP1, in order to block cleavage of p25, leads to the production of noninfectious viral particles with aberrant core morphology [40]. In addition, treatment of virus producing cells with 3-O-(3'-3'dimethylsuccinyl) betulinic acid (BVM, Bevirimat, also known as PA-457 or DSB), a specific inhibitor that blocks PR-mediated cleavage between $\mathrm{CA}$ and SP1, disturbed viral core formation [43]. Intriguingly, mutation of Ser-40 leads to an almost identical aberrant virus core morphology as shown previously for CA5 mutants. Both are characterized by misshapen core structures and the formation of an electron dense lateral body near the viral membrane. Previous studies already indicated that maturation of HIV-1 virions, leading to the typical cone shaped cores, is regulated by the sequential, and highly ordered proteolytic cleavage of Gag [40]. Apparently, the last step of Gag processing the cleavage of the CA-SP1 junction - is required for capsid condensation. However, pulse chase data indicate that the kinetic of cleavage of the CA-SP1 junction is delayed, but not completely blocked inasmuch as the mature CA accumulates over time. This indicates a rather dynamic process in which the mutation of Ser-40 somehow delays the kinetic of CA maturation. This phenomenon correlates with deficiencies in CA processing, infectivity, and core morphology.

Recently published results from Müller et al. demonstrate that even low amounts of Gag processing intermediates interfere with HIV particle maturation in a trans-dominant manner, with the final cleavage between p24 and SP1 being of particular importance [44]. This explains why the rather subtle effect on CA maturation detected for Ser-40 mutants by Western blotting and pulse chase analysis results in a substantial reduction of virus core formation.

Interestingly, the effect of the S40F mutation appears to be specific for the CA-SP1 cleavage inasmuch as i) no other Gag processing deficiency could be detected 
(Figure 6) and ii) enhancing CA processing by introducing the A1V mutation could restore the deficient core formation, and, consequently, enhance infectivity. Thus, it can be concluded that Ser-40 somehow regulates the cleavage of the CA-SP1 junction and the subsequent capsid condensation.

The molecular mechanism behind how Ser-40 regulates the processing of Gag, in particular the cleavage of the CA-SP1 junction, is still elusive so far. The previously described defects in Gag processing commonly observed for L-domain mutants are believed to be linked to the overall process of virus budding inasmuch as PR activation and subsequent Gag processing occur concomitantly with and shortly after release of virus particles $[45,46]$. In the case of Ser-40, this can be excluded, as the mutant S40F exhibits $w t$ budding. However, Ser-40 in $\mathrm{p} 6$ and the CA-SP1 junction are separated by 123 amino acids in $\operatorname{Pr} 55$ and it remains elusive so far, how both proteins can affect each other, either in the context of Pr55 or after Gag processing. Our NMR experiments demonstrated that the C-terminal structure of p6 is not influenced by the S40F mutation. Therefore, one possibility of the effect observed would be that the mutation affects the Gag structure prior to initiation of Gag processing, thereby reducing the cleavage efficiency of the weakest cleavage site in Pr55. A prerequisite for this scenario would be that p6 represents a structured Gag domain and thus influence the folding the Pr55 polyprotein. Even though the 283 residue N-terminal part of HIV-1 Gag including MA and CA has been solved by NMR [47], the structure of the complete Pr55 has not been determined hitherto. Although S40F does not appear to affect the folding of the mature p6 protein, we can not exclude that this mutation indeed affect the overall structure of the PR55 polyprotein, which in turn would reduce the processing efficiency, a phenotype we clearly observed for the S40F mutant as a novel function of p6.

Currently, there is no evidence of an intra-molecular interaction between these domains in the Pr55 polyprotein. The p6 domain of the Pr55 represents a docking site of several cellular and viral factors. Thus, since an intramolecular interaction between CA and p6 appears to be unlikely, it is conceivable to hypothesize that $\mathrm{p} 6$ harbors another interaction domain of a yet unknown factor that, independently of the L-domains, regulates processing of CA.

\section{Conclusions}

Overall, these data support a so far unrecognized function of p6 that occurs independently of the L-domain function, does not affect virus release, but selectively affects CA maturation, virus core formation, and thus, infectivity.

\section{Methods}

\section{Peptide synthesis and purification}

The synthesis, purification and molecular characterization of $\mathrm{p} 6$ and the related fragments derived from HIV$1_{\mathrm{NL4-3}}$ have been described in detail previously [25].

\section{NMR Spectroscopy}

$2 \mathrm{D}^{1} \mathrm{H}$ Total Correlation Spectroscopy (TOCSY), Correlation Spectroscopy (COSY) and Nuclear Overhauser enhancement spectroscopy (NOESY) NMR experiments were performed at $600.13 \mathrm{MHz}$ on a Bruker Avance $600 \mathrm{MHz}$ instrument equipped with an UltraShield Plus magnet and a triple resonance cryoprobe with gradient unit. Individual samples were dissolved in $600 \mu \mathrm{l} 50 \%$ aqueous TFE-d2 at concentrations between 1-2 mM. The 2D NMR experiments were performed at $300 \mathrm{~K}$ without spinning with mixing times of $110 \mathrm{~ms}$ for the TOCSY experiments and $250 \mathrm{~ms}$ for the NOESY experiments, respectively. Efficient suppression of the water signal was achieved with application of excitation sculpting in the $1 \mathrm{D}{ }^{1} \mathrm{H}$ and the 2D ${ }^{1} \mathrm{H}$ TOCSY and NOESY NMR experiments. ${ }^{1} \mathrm{H}$ signal assignments of the NMR spectra were achieved by identification of the individual spin systems in the 2D ${ }^{1} \mathrm{H}$ TOCSY spectra, combined with observations of sequence-specific shortdistance crosspeaks $\left(\mathrm{H}_{\alpha}-\mathrm{HN} \mathrm{i}, \mathrm{i}+1\right)$ in the $2 \mathrm{D}{ }^{1} \mathrm{H}-{ }^{1} \mathrm{H}$ NOESY spectra $[48,49]$. Readily recognizable spin systems were used as starting points for correlation of the individual spin systems observed in the TOCSY and NOESY spectra with individual residues in the peptide sequences. Acquisition of data, processing and spectral analysis were performed with Bruker Topspin 1.3 software.

\section{Antibodies}

Antibody specific for FLAG was obtained from Sigma, the ribosomal $\mathrm{P}$ antigen specific antiserum from Immunovision Inc., the CA specific antiserum from Seramun. The p6 specific antibody was described earlier [25]. The anti-mouse, anti-rabbit, and anti-human IgG antibodies coupled to horseradish peroxidase (HRP) were obtained from Amersham.

\section{DNA mutagenesis}

Amino acid exchanges at Ser-40 in p6 were introduced by site-directed mutagenesis using oligonucleotides containing the indicated changes (S40F, $\triangle \mathrm{YP}$, and $\triangle \mathrm{PTAP}$ ) and the Quick Change ${ }^{\circledR}$ site directed mutagenesis kit (Stratagene). The mutations were introduced in the X4tropic $\mathrm{HIV}-1_{\mathrm{NL} 4-3}$ infectious molecular clone [28] and isogenic R5-tropic derivative thereof [30]. In order to avoid taking biosafety measures, the mutations were also introduced in two HIV-1 $1_{\mathrm{NL} 4-3}$ based subgenomic expression vectors giving rise to noninfectious VLPs: the 
pNLenv, in which env was deleted [50], and a an HIV-1 expression construct that carries a primer binding site deletion, as well as two point mutations in the active site of the $\mathrm{RT}$ coding region ( $\mathrm{p} \Delta \mathrm{R}$ [51]). All introduced mutations did not lead to mutations in the overlapping pol-ORF.

\section{Cell culture}

HeLa SS6, HeLa TZM-bl and 293T cells were cultured in Dulbecco's modified Eagle's medium (DMEM) supplemented with $10 \%(\mathrm{v} / \mathrm{v})$ inactivated fetal calf serum (FCS), $2 \mathrm{mM}$ L-glutamine, $100 \mathrm{U} / \mathrm{ml}$ penicillin and $100 \mu \mathrm{g} / \mathrm{ml}$ streptomycin. CEM cells were maintained in RPMI 1640 supplemented with 10\% (v/v) inactivated FCS, $2 \mathrm{mM}$ L-glutamine, $100 \mathrm{U} / \mathrm{ml}$ penicillin and $100 \mu \mathrm{g} / \mathrm{ml}$ streptomycin. All media and compounds were provided by Gibco.

\section{Preparation and cultivation of primary cells}

Human tonsils, removed during routine tonsillectomy, were received a few hours after excision from the Olgahospital, Stuttgart, Germany, prepared and infected as described earlier [32,33]. After washing the tonsils, human lymphocyte aggregate cultures (HLAC) were prepared by dividing the tonsils into tissue blocks of 2-3 $\mathrm{mm}$ and grinding the tissue through the sieve of a cell strainer (70 $\mu \mathrm{m}, \mathrm{BD}$ Falcon) with a syringe plunger. Cells were seeded in a 96 well plate at a concentration of $2 \times 10^{6}$ cells per well. HLACs were cultured in RPMI 1640 supplemented with $15 \%(\mathrm{v} / \mathrm{v})$ inactivated FCS, 2 $\mathrm{mM}$ L-glutamine, $100 \mathrm{U} / \mathrm{ml}$ penicillin and $100 \mu \mathrm{g} / \mathrm{ml}$ streptomycin, $2.5 \mu \mathrm{g} / \mathrm{ml}$ Fungizone, $1 \mathrm{mM}$ sodium pyruvate, $1 \%(\mathrm{v} / \mathrm{v})$ MEM non-essential amino acid solution and $50 \mu \mathrm{g} / \mathrm{ml}$ gentamicin.

\section{Western blot for protein analysis}

HeLa SS6 cells were transiently transfected with the appropriate DNA using Lipofectamine 2000 ${ }^{\mathrm{TM}}$ (Invitrogen) according to the manufacturer's protocol. For ALIX cotransfection, 293T cells were transfected with equal amounts of both DNAs and cells were harvested $24 \mathrm{~h}$ post transfection. Cells were lysed in cold RIPA buffer (50 mM Tris- $\mathrm{HCl} \mathrm{pH} 7.4,150 \mathrm{mM} \mathrm{NaCl}, 1 \%$ Nonidet P-40, 0.5\% sodium deoxycholat, 0.1\% Na-SDS, $5 \mathrm{mM}$ EDTA, DNase, $1 \mathrm{mM}$ PMSF and complete protease inhibitor cocktail (Boehringer Mannheim)), and the lysates were cleared by centrifugation at $16000 \times g$ and $4{ }^{\circ} \mathrm{C}$ for $10 \mathrm{~min}$. RIPA-soluble proteins and VLPs were separated in $10 \%$ SDS/PAA gels, according to Laemmli [52], transferred onto PVDF membranes (GE Healthcare) and probed with specific antibodies, followed by enhanced chemiluminescence detection. For internal controls, blots were stripped and re-incubated with the appropriate antibody.

\section{Metabolic labeling and immunoprecipitation}

For pulse chase experiments, adherent cultures of transfected HeLa SS6 cells were washed once with PBS and starved for $30 \mathrm{~min}$ in methionine-free, serum-free RPMI 1640. Cells were pulse-labeled for $15 \mathrm{~min}$ with $\left[{ }^{35} \mathrm{~S}\right]$ methionine (3 $\mathrm{mCi} / \mathrm{ml}$; Amersham Life Sciences) and chased for up to $4 \mathrm{~h}$ while shaking at $37^{\circ} \mathrm{C}$ in D-MEM, supplemented with $10 \%$ FCS and $10 \mathrm{mM}$ methionine. At the indicated time points, cells and supernatants were collected by centrifugation for $1 \mathrm{~min}$ at $16000 \times g$. Virions were pelleted through a $20 \%(\mathrm{w} / \mathrm{v})$ sucrose cushion and lysed in Triton wash buffer $(50 \mathrm{mM}$ Tris- $\mathrm{HCl}$ pH 7.4, $300 \mathrm{mM} \mathrm{NaCl}, 0.1 \%$ Triton X-100, $1 \mathrm{mM}$ PMSF). Cells were lysed in RIPA buffer as described above, containing additionally $5 \mathrm{mM} \mathrm{N}$-ethylmaleimide and $20 \mu \mathrm{M}$ carbobenzoxyl-Leu-Leu-leucinal (zLLL; Sigma). Gag proteins from precleared cell lysates and lysed VLPs were recovered by immunoprecipitation using a mixture of polyclonal rabbit anti-p6 and antip24 antibodies prebound to protein G-Sepharose (GE Healthcare). Samples were separated by SDS-PAGE on a $10 \%(\mathrm{w} / \mathrm{v})$ acryl amide ProSieve gel (Cambrex Bioscience), backed with Gel Bond film (FMC Bioproducts). Following fixation for $1 \mathrm{~h}$ in $50 \%$ methanol and $10 \%$ acetic acid, gels were rinsed with water, soaked in $1 \mathrm{M}$ sodium salicylic acid solution with $10 \%$ glycerol for $5 \mathrm{~h}$ and dried. Radioactivity in dried gels was quantified using AIDA imaging software (Raytest).

\section{Viruses}

Virus containing cell culture supernatant was harvested after $48 \mathrm{~h}$ and, after removal of residual cells by centrifugation, passed through a $0.45 \mu \mathrm{m}$ pore-size filter. Virus was pelleted through $20 \%(\mathrm{w} / \mathrm{v})$ sucrose $(16000 \times$ $\left.g, 4^{\circ} \mathrm{C}, 90 \mathrm{~min}\right)$. Virus stocks were normalized for $\mathrm{p} 24$ content as quantified by a enzyme-linked immunosorbent assay (ELISA, Aalto, Dublin, Ireland) and aliquots were stored at $-80^{\circ} \mathrm{C}$.

\section{Infection of cells}

For infection of T cell cultures, $1 \times 10^{7}$ cells were incubated with 20 or $50 \mathrm{ng}$ of p24, respectively, and supernatant was collected every second day post infection. Virus replication was assessed by quantification of the virus-associated $\mathrm{RT}$ activity by $\left[{ }^{32} \mathrm{P}\right]$-TTP incorporation using an oligo(dT)-poly(A) template as described [53]. For testing each virus in the HLAC from one donor, $1 \mathrm{ng}$ of p24 was applied to $2 \times 10^{6}$ cells in 96 well format, and virus replication was assessed, as described for $\mathrm{T}$ cell cultures, every third day post infection.

\section{Viral infectivity assay}

HeLa TZM-bl cells were seeded in 96 well format (4000 cells per well) and infected with standardized amount 
of p24. The next day, fresh medium with $100 \mu \mathrm{g} / \mathrm{ml}$ dextran sulphate was added to prevent further spread of virus infection, and cells were incubated for further two days. Infection was detected using a galactosidase screen kit from Tropix as recommended by the manufacturer. $\beta$-Galactosidase activity was quantified as relative light units per second using an Orion Microplate Luminometer (Berthold).

\section{Transmission electron microscopy (TEM)}

Transfected HeLa SS6 cells were processed for transmission electron microscopy in the following way: $24 \mathrm{~h}$ post transfection, cells were placed in cellulose capillary tubes [54], cultivated for one more day, then fixed in $2.5 \%$ glutaraldehyde for $1 \mathrm{~h}$ at $37^{\circ} \mathrm{C}$ and stored for further preparation at $4^{\circ} \mathrm{C}$. Tubes were collected by centrifugation and sealed by immersion in low-melting-point agarose. The samples were post fixed with $\mathrm{OsO}_{4}(1 \%$ in distilled water, $1 \mathrm{~h}$ ), tannic acid ( $0.1 \%$ in Hepes $0,05 \mathrm{M}, 30 \mathrm{~min}$ ) and uranyl acetate ( $1 \%$ in distilled water, $2 \mathrm{~h}$ ) followed by stepwise dehydration in a graded ethanol series and embedding in epon resin, which was subsequently polymerized. Thin sections were prepared with an ultramicrotome (Ultracut S; Leica, Wetzlar, Germany) and counterstained with uranyl acetate and lead citrate. The sections were examined using a TEM 902 (Carl Zeiss SMT AG) at $80 \mathrm{kV}$, and the images were digitized using a slow-scan charge-coupled-device camera (Pro Scan; Scheuring, Germany). The evaluation of the capsid morphology was performed by using these images or directly on the screen.

\section{Acknowledgements \\ We thank Dr. Henning Heumann and the surgical staff of the Olgahospital, Stuttgart, for generous assistance in obtaining post-tonsillectomy samples, Raymond Sowder for HPLC purification, and Victor Wray for critical reading of the manuscript. This work was supported by a grant IE-S08T06 from the German Human Genome Research Project, by grants SFB 643-A1, \\ SCHU1125/3, and SCHU 1125/5, from the German Research Council to US.}

\section{Author details}

${ }^{1}$ Institute of Virology, Friedrich-Alexander-University, Erlangen, Germany. ${ }^{2}$ Centre of Pharmacy, University of Bergen, Bergen Norway. ${ }^{3}$ Institute of Biochemistry, Humboldt University, Berlin, Germany. ${ }^{4}$ SAIC-Frederick, Inc., National Cancer Institute, Frederick, USA. ${ }^{5}$ Robert Koch-Institute, Berlin, Germany.

\section{Authors' contributions}

US designed the study. LN, SH, FH, PR, KS, NS and JV performed virus replications, infectivity as well as Western blot and pulse chase analysis of virions. SMØS and TF performed NMR studies, PH synthesized the peptides and DEO supplied essential material. NB and GH did the electron microscopy. JV and US wrote the manuscript. All authors read and approved the final manuscript.

\section{Competing interests}

The authors declare that they have no competing interests.

Received: 5 November 2010 Accepted: 16 February 2011 Published: 16 February 2011
References

1. Wills JW, Craven RC: Form, function, and use of retroviral gag proteins. Aids 1991, 5(6):639-654.

2. Turner BG, Summers MF: Structural biology of HIV. J Mol Biol 1999, 285(1):1-32.

3. Kräusslich HG, Welker R: Intracellular transport of retroviral capsid components. Curr Top Microbiol Immunol 1996, 214:25-63.

4. Vogt VM: Ubiquitin in retrovirus assembly: actor or bystander? Proc Natl Acad Sci USA 2000, 97(24):12945-12947.

5. Swanstrom R, Wills JW: Retroviral gene expression: synthesis, processing, and assembly of viral proteins. In Retroviruses. Edited by: Coffin JM, Hughes SH. Varmus HE: Cold Spring Harbor Laboratory Press, Cold Spring Harbor, N.Y; 1997:263-334.

6. Vogt VM: Retroviral virions and genomes. In Retroviruses. Edited by: Coffin JM, Hughes SH. Varmus HE: Cold Spring Harbor Laboratory Press, Cold Spring Harbor, N.Y; 1997:27-70.

7. Pornillos O, Garrus JE, Sundquist WI: Mechanisms of enveloped RNA virus budding. Trends Cell Biol 2002, 12(12):569-579.

8. Göttlinger HG, Dorfman T, Sodroski JG, Haseltine WA: Effect of mutations affecting the $\mathrm{p} 6 \mathrm{gag}$ protein on human immunodeficiency virus particle release. Proc Natl Acad Sci USA 1991, 88(8):3195-3199.

9. Freed EO: Viral late domains. J Virol 2002, 76(10):4679-4687.

10. Greene WC, Peterlin BM: Charting HIV's remarkable voyage through the cell: Basic science as a passport to future therapy. Nat Med 2002, 8(7):673-680.

11. Perez OD, Nolan GP: Resistance is futile: assimilation of cellular machinery by HIV-1. Immunity 2001, 15(5):687-690.

12. Luban J: HIV-1 and Ebola virus: the getaway driver nabbed. Nat Med 2001, 7(12):1278-1280.

13. Strack B, Calistri A, Craig S, Popova E, Göttlinger HG: AIP1/ALIX is a binding partner for HIV-1 p6 and EIAV p9 functioning in virus budding. Cell 2003, 114(6):689-699.

14. Carlton JG, Martin-Serrano J: Parallels between cytokinesis and retroviral budding: a role for the ESCRT machinery. Science 2007, 316(5833):1908-1912.

15. Martin-Serrano J, Zang T, Bieniasz PD: HIV-1 and Ebola virus encode small peptide motifs that recruit Tsg101 to sites of particle assembly to facilitate egress. Nat Med 2001, 7(12):1313-1319.

16. von Schwedler UK, Stuchell M, Müller B, Ward DM, Chung HY, Morita E, Wang HE, Davis T, He GP, Cimbora DM, et al: The protein network of HIV budding. Cell 2003, 114(6):701-713.

17. Pornillos O, Alam SL, Rich RL, Myszka DG, Davis DR, Sundquist Wl: Structure and functional interactions of the Tsg101 UEV domain. Embo J 2002, 21(10):2397-2406.

18. Garrus JE, von Schwedler UK, Pornillos OW, Morham SG, Zavitz KH, Wang HE, Wettstein DA, Stray KM, Cote M, Rich RL, et al: Tsg101 and the vacuolar protein sorting pathway are essential for HIV-1 budding. Cell 2001, 107(1):55-65.

19. Myers EL, Allen JF: Tsg101, an inactive homologue of ubiquitin ligase e2, interacts specifically with human immunodeficiency virus type 2 Gag polyprotein and results in increased levels of ubiquitinated Gag. J Virol 2002, 76(22):11226-11235.

20. VerPlank L, Bouamr F, LaGrassa TJ, Agresta B, Kikonyogo A, Leis J, Carter CA: Tsg101, a homologue of ubiquitin-conjugating (E2) enzymes, binds the L domain in HIV type 1 Pr55 ${ }^{\mathrm{Gag}}$. Proc Natl Acad Sci USA 2001, 98(14):7724-7729.

21. Fisher RD, Chung HY, Zhai Q, Robinson H, Sundquist WI, Hill CP: Structural and biochemical studies of ALIX/AIP1 and its role in retrovirus budding. Cell 2007, 128(5):841-852.

22. Kondo $E$, Göttlinger HG: A conserved LXXLF sequence is the major determinant in p6gag required for the incorporation of human immunodeficiency virus type 1 Vpr. J Virol 1996, 70(1):159-164.

23. Salgado GF, Marquant R, Vogel A, Alves ID, Feller SE, Morellet N, Bouaziz S. Structural studies of HIV-1 Gag p6ct and its interaction with Vpr determined by solution nuclear magnetic resonance. Biochemistry 2009, 48(11):2355-2367.

24. Zhu H, Jian H, Zhao LJ: Identification of the 15FRFG domain in HIV-1 Gag p6 essential for Vpr packaging into the virion. Retrovirology 2004, 1:26.

25. Fossen T, Wray V, Bruns K, Rachmat J, Henklein P, Tessmer U, Maczurek A, Klinger $P$, Schubert $U$ : Solution structure of the human immunodeficiency virus type 1 p6 protein. J Biol Chem 2005, 280(52):42515-42527. 
26. Munshi UM, Kim J, Nagashima K, Hurley JH, Freed EO: An Alix fragment potently inhibits HIV-1 budding: characterization of binding to retroviral YPXL late domains. J Biol Chem 2007, 282(6):3847-3855.

27. Zhai Q, Fisher RD, Chung HY, Myszka DG, Sundquist WI, Hill CP: Structural and functional studies of ALIX interactions with $Y_{P X} L$ late domains of HIV-1 and EIAV. Nat Struct Mol Biol 2008, 15(1):43-49.

28. Adachi A, Gendelman HE, Koenig S, Folks T, Willey R, Rabson A, Martin MA: Production of acquired immunodeficiency syndrome-associated retrovirus in human and nonhuman cells transfected with an infectious molecular clone. J Virol 1986, 59(2):284-291.

29. Lazert C, Chazal N, Briant L, Gerlier D, Cortay JC: Refined study of the interaction between HIV-1 p6 late domain and ALIX. Retrovirology 2008, 5:39.

30. Papkalla A, Münch J, Otto C, Kirchhoff F: Nef enhances human immunodeficiency virus type 1 infectivity and replication independently of viral coreceptor tropism. J Virol 2002, 76(16):8455-8459.

31. Eckstein DA, Penn ML, Korin YD, Scripture-Adams DD, Zack JA, Kreisberg JF, Roederer M, Sherman MP, Chin PS, Goldsmith MA: HIV-1 actively replicates in naive $\mathrm{CD}^{+} \mathrm{T}$ cells residing within human lymphoid tissues. Immunity 2001, 15(4):671-682.

32. Glushakova S, Baibakov B, Margolis LB, Zimmerberg J: Infection of human tonsil histocultures: a model for HIV pathogenesis. Nat Med 1995, 1(12):1320-1322

33. Glushakova S, Baibakov B, Zimmerberg J, Margolis LB: Experimental HIV infection of human lymphoid tissue: correlation of $\mathrm{CD}^{+} \mathrm{T}$ cell depletion and virus syncytium-inducing/non-syncytium-inducing phenotype in histocultures inoculated with laboratory strains and patient isolates of HIV type 1. AIDS Res Hum Retroviruses 1997, 13(6):461-471.

34. Clavel F, Hoggan MD, Willey RL, Strebel K, Martin MA, Repaske R: Genetic recombination of human immunodeficiency virus. J Virol 1989, 63(3):1455-1459.

35. Maldarelli F, Martin MA, Strebel K: Identification of posttranscriptionally active inhibitory sequences in human immunodeficiency virus type 1 RNA: novel level of gene regulation. J Virol 1991, 65(11):5732-5743.

36. Fujii K, Munshi UM, Ablan SD, Demirov DG, Soheilian F, Nagashima K, Stephen AG, Fisher RJ, Freed EO: Functional role of Alix in HIV-1 replication. Virology 2009, 391(2):284-292.

37. Usami Y, Popov S, Göttlinger HG: Potent rescue of human immunodeficiency virus type 1 late domain mutants by ALIX/AIP1 depends on its CHMP4 binding site. J Virol 2007, 81(12):6614-6622.

38. Huang $M$, Orenstein JM, Martin MA, Freed EO: $p 6^{\text {Gag }}$ is required for particle production from full-length human immunodeficiency virus type 1 molecular clones expressing protease. J Virol 1995, 69(11):6810-6818.

39. Ott DE, Chertova EN, Busch LK, Coren LV, Gagliardi TD, Johnson DG: Mutational analysis of the hydrophobic tail of the human immunodeficiency virus type $1 \mathrm{p} 6^{\mathrm{Gag}}$ protein produces a mutant that fails to package its envelope protein. J Virol 1999, 73(1):19-28.

40. Wiegers K, Rutter G, Kottler H, Tessmer U, Hohenberg H, Kräusslich HG: Sequential steps in human immunodeficiency virus particle maturation revealed by alterations of individual Gag polyprotein cleavage sites. J Virol 1998, 72(4):2846-2854.

41. Pettit SC, Moody MD, Wehbie RS, Kaplan AH, Nantermet PV, Klein CA, Swanstrom R: The p2 domain of human immunodeficiency virus type 1 Gag regulates sequential proteolytic processing and is required to produce fully infectious virions. J Virol 1994, 68(12):8017-8027.

42. Pettit SC, Henderson GJ, Schiffer CA, Swanstrom R: Replacement of the P1 amino acid of human immunodeficiency virus type 1 Gag processing sites can inhibit or enhance the rate of cleavage by the viral protease. $J$ Virol 2002, 76(20):10226-10233

43. Li F, Goila-Gaur R, Salzwedel K, Kilgore NR, Reddick M, Matallana C, Castillo A, Zoumplis D, Martin DE, Orenstein JM, et al: PA-457: a potent HIV inhibitor that disrupts core condensation by targeting a late step in Gag processing. Proc Natl Acad Sci USA 2003, 100(23):13555-13560.

44. Müller B, Anders M, Akiyama H, Welsch S, Glass B, Nikovics K, Clavel F, Tervo HM, Keppler OT, Kräusslich HG: HIV-1 Gag processing intermediates trans-dominantly interfere with HIV-1 infectivity. J Biol Chem 2009, 284(43):29692-29703.

45. Kaplan AH, Swanstrom R: Human immunodeficiency virus type $1 \mathrm{Gag}$ proteins are processed in two cellular compartments. Proc Natl Acad SC USA 1991, 88(10):4528-4532.
46. Kaplan $\mathrm{AH}$, Manchester M, Swanstrom R: The activity of the protease of human immunodeficiency virus type 1 is initiated at the membrane of infected cells before the release of viral proteins and is required for release to occur with maximum efficiency. J Virol 1994, 68(10):6782-6786

47. Tang C, Ndassa Y, Summers MF: Structure of the N-terminal 283-residue fragment of the immature HIV-1 Gag polyprotein. Nat Struct Biol 2002, 9(7):537-543.

48. Bruns K, Fossen T, Wray V, Henklein P, Tessmer U, Schubert U: Structural characterization of the HIV-1 Vpr N terminus: evidence of cis/transproline isomerism. J Biol Chem 2003, 278(44):43188-43201.

49. Wüthrich K: NMR of Proteins and Nucleic Acids. New York: John Wiley \& Sons, Inc; 1986.

50. Schubert U, Clouse KA, Strebel K: Augmentation of virus secretion by the human immunodeficiency virus type $1 \mathrm{Vpu}$ protein is cell type independent and occurs in cultured human primary macrophages and lymphocytes. J Virol 1995, 69(12):7699-7711.

51. Gottwein $E$, Kräusslich HG: Analysis of human immunodeficiency virus type 1 Gag ubiquitination. J Virol 2005, 79(14):9134-9144.

52. Laemmli UK: Cleavage of structural proteins during the assembly of the head of bacteriophage T4. Nature 1970, 227(5259):680-685.

53. Willey RL, Smith DH, Lasky LA, Theodore TS, Earl PL, Moss B, Capon DJ, Martin MA: In vitro mutagenesis identifies a region within the envelope gene of the human immunodeficiency virus that is critical for infectivity. J Virol 1988, 62(1):139-147.

54. Hohenberg H, Mannweiler K, Müller M: High-pressure freezing of cell suspensions in cellulose capillary tubes. J Microsc 1994, 175(Pt 1):34-43.

55. Hemonnot B, Cartier C, Gay B, Rebuffat S, Bardy M, Devaux C, Boyer V, Briant $L$ : The host cell MAP kinase ERK-2 regulates viral assembly and release by phosphorylating the p6gag protein of HIV-1. J Biol Chem 2004, 279(31):32426-32434

56. Ott DE, Coren LV, Copeland TD, Kane BP, Johnson DG, Sowder RC, Yoshinaka Y, Oroszlan S, Arthur LO, Henderson LE: Ubiquitin is covalently attached to the $\mathrm{p} 6^{\mathrm{Gag}}$ proteins of human immunodeficiency virus type 1 and simian immunodeficiency virus and to the $\mathrm{p} 12^{\mathrm{Gag}}$ protein of Moloney murine leukemia virus. J Virol 1998, 72(4):2962-2968.

57. Gurer C, Berthoux L, Luban J: Covalent modification of human immunodeficiency virus type 1 p6 by SUMO-1. J Virol 2005, 79(2):910-917.

58. Demirov DG, Ono A, Orenstein JM, Freed EO: Overexpression of the Nterminal domain of TSG101 inhibits HIV-1 budding by blocking late domain function. Proc Natl Acad Sci USA 2002, 99(2):955-960.

doi:10.1186/1742-4690-8-11

Cite this article as: Votteler et al:: Highly conserved serine residue 40 in HIV-1 p6 regulates capsid processing and virus core assembly. Retrovirology 2011 8:11.

\section{Submit your next manuscript to BioMed Central and take full advantage of:}

- Convenient online submission

- Thorough peer review

- No space constraints or color figure charges

- Immediate publication on acceptance

- Inclusion in PubMed, CAS, Scopus and Google Scholar

- Research which is freely available for redistribution

Submit your manuscript at www.biomedcentral.com/submit
C Biomed Central 